\title{
JRRD
}

\section{Elastic head support for persons with amyotrophic lateral sclerosis}

\author{
Andrew Hansen, PhD; $;^{1-2 *}$ Beau Bedore, MA ${ }^{1}$ Eric Nickel, MS ${ }^{1}{ }^{K r i s t i n}$ Hanowski, DPT $;{ }^{1}$ Sonya Tangen, MS, \\ OTR/L, ATP; ${ }^{1}$ Gary Goldish, MD ${ }^{1-2}$ \\ ${ }^{1}$ Minneapolis Department of Veterans Affairs Health Care System, Minneapolis, MN; ${ }^{2}$ Department of Physical Medicine \\ and Rehabilitation, University of Minnesota, Minneapolis, $M N$
}

\begin{abstract}
This article describes an inexpensive elastic head support for persons with amyotrophic lateral sclerosis (ALS) and neck muscle weakness and also presents a case series to examine its effectiveness. The device offers support to the head while the user is seated, standing, and walking, providing support for persons in various stages of ALS. The head support system was tested in seven male patients with ALS. Before and after the 2 wk trial, the subjects answered questions related to their communication efficacy, difficulty swallowing, level of neck discomfort, number of hours being upright before neck discomfort, comfort in social settings, and rating of perceived dyspnea. Subjects also answered specific questions related to the elastic head support after the 2 wk trial. The results suggested that the elastic head support is useful for some, but not all, patients.
\end{abstract}

Key words: amyotrophic lateral sclerosis, braces, cervical orthosis, elastic head support, head, neck, neck muscle weakness, orthotic devices, range of motion, rehabilitation.

\section{INTRODUCTION}

Numerous head support systems (cervical orthoses) are available for persons with neck muscle weakness or cervical injuries. These systems are sometimes used by persons with amyotrophic lateral sclerosis (ALS) who have lost strength in the neck extensors or who experience neck muscle fatigue or soreness [1]. Some cervical orthoses provide support that is excessive for persons with neck muscle weakness (e.g., sternal occipital mandibular immobilizer) or provide support only when seated in a wheelchair. Other simple systems exist, such as a neck collar or
Headmaster Collar, that can be used during seated or standing postures. However, these systems hold the chin and can restrict activities such as eating, talking, or turning the head. Over extended periods of time, the pressure on the chin can also become uncomfortable.

The purpose of our project was to design and test a simple head support system that could be used for seated and upright postures (standing or walking) and would not interfere with the user's chin. The project was motivated by a perceived need for simple head support systems for persons with ALS, although the device may be useful for other persons with neck muscle weakness or fatigue. We hypothesized that the new design would be perceived as useful by ALS patients with neck muscle weakness and would be preferred over other devices they were using (when applicable). We also collected pilot data on other outcomes that could be affected by using the device: eating and swallowing, perceived feeling of breathlessness, and communication efficacy.

During the conduct of our study, we became aware of a similar head support system named the "baseball cap orthosis" [2]. Comparison with the baseball cap orthosis

\footnotetext{
Abbreviations: ALS = amyotrophic lateral sclerosis, EAT-10 = Eating Assessment Tool, VA = Department of Veterans Affairs. *Address all correspondence to Andrew Hansen, PhD; Minneapolis VA Health Care System, One Veterans Drive, Research-MS 151, Minneapolis, MN 55417; 612-467-2910; fax: 612-725-2093. Email: andrew.hansen2@va.gov http://dx.doi.org/10.1682/JRRD.2013.03.0072
} 
is discussed, including perceived advantages and disadvantages of the two approaches. To our knowledge, neither of these devices has previously been tested in persons with ALS.

\section{METHODS}

\section{Design of Elastic Head Support System}

The elastic head support system used in this study comprised an elastic strap connecting the back of the pants to the back of a baseball cap (Figure 1). For our study, we used a 2 in.-wide neoprene strap with a Velcro ${ }^{\circledR}$ pile on one side and a rubber core (Item A8105, Patterson Medical; Bolingbrook, Illinois) anchored to the belt or pants to provide the elastic support. The baseball caps had Velcro closures in the back with enough strength to hold together when subjected to sufficient tension to support the weight of a person's head. The neoprene strap was $1 / 8 \mathrm{in}$. thick
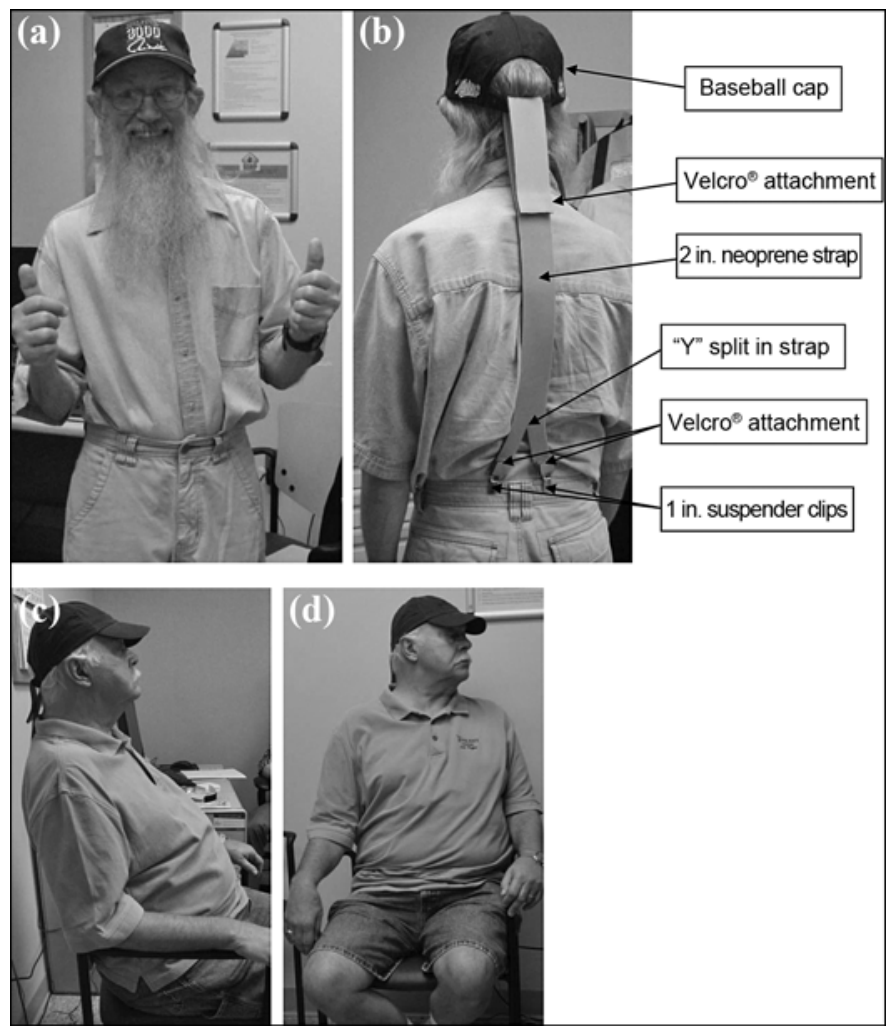

\section{Figure 1.}

Elastic head support system from (a) front, (b) back, and (c) side. (d) Elastic head support provides support while allowing for transverse rotation of head. and 2 in. wide and initially cut to a length of approximately 36 in. One end of the neoprene strap was split in half ("Y" cut to create two sides $1 \mathrm{in}$. wide) for approximately $10 \mathrm{in}$. The 1 in. straps were either looped around the subject's belt or looped through $1 \mathrm{in}$. suspender clips that could be attached to the subject's pants or shorts. Two-sided pieces of Velcro hooks were created by sticking two adhesivebacked hook pieces together. These hook-to-hook pieces were used to create Velcro attachments at the connection of the strap to the hat and the connection with suspender clips (Figure 1). The head support system can be used on the outside of the shirt (Figure 1) or underneath a shirt that is not tucked into the pants (Figure 2).

\section{Testing of Elastic Head Support System}

ALS patients with neck muscle weakness or fatigue who were having difficulty maintaining their head position during activities of daily living and who were being considered for a head support system were recruited for the study. Research subjects first went through a consent process approved by the Minneapolis Department of Veterans Affairs (VA) Institutional Review Board. After consent on the appropriate forms was documented, the cervical range of motion of the research subjects while in a seated position was measured using a microFET3 (Hoggan Health; Salt Lake City, Utah). Active range of motion was measured in both flexion and extension by using the
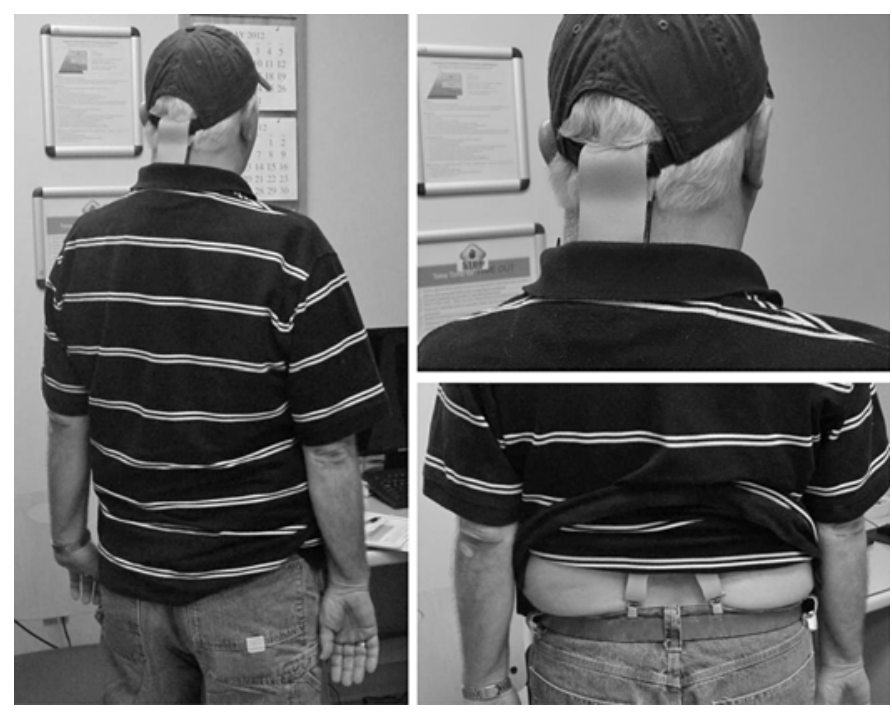

\section{Figure 2.}

Use of elastic head support system under shirt that is not tucked into pants. 
manufacturer's recommended protocol. The passive range of motion was also measured for extension because the elastic head support is designed to assist in this direction. After completing the range of motion testing, the subjects went through the following standard questionnaires:

- Modified Borg Scale-Rating of Perceived Dyspnea [3-5]: Assesses the subject's perceived degree of breathlessness. The scale ranges from 0 (no breathlessness at all) to 10 (maximum breathlessness).

- Communication Effectiveness Scale for Individuals with ALS [6]: Assesses the subject's perceived difficulty with communication with others. The scale includes 10 questions about communication. The scale ranges from 1 (not understood) to 5 (effectively understood). The total score is the average of the responses (i.e., between 1 and 5).

- Eating Assessment Tool (EAT-10) [7]: Assesses the subject's perceived difficulty swallowing. The tool asks 10 questions about swallowing. The scale ranges from 0 (no problem) to 4 (severe problem). The total score is the sum of the responses (i.e., minimum of 0 and maximum of 40).

The subjects were also given a custom questionnaire before using the device (Appendix 1, available online only). After the subjects filled out the questionnaires, they were fitted with the elastic head support system and allowed to leave. The subjects were instructed to use the elastic head support whenever they wanted (i.e., whenever they felt it would be useful). For ecological validity of the study, the subjects were also encouraged to use other head support systems they already had during the same time if they preferred.

After $2 \mathrm{wk}$, the research subjects returned to the medical center and answered the same questions from the first visit (Rating of Perceived Dyspnea, Communication Effectiveness Scale, EAT-10, and questionnaire in Appendix 1), as well as additional questions related specifically to the elastic head support (Appendix 2, available online only). In addition to the structured questions, the research subjects were encouraged to provide any other feedback they thought would be useful for future users of the elastic head support.

\section{RESULTS}

Seven men with ALS were recruited for the study and were fitted with the elastic head support system. Six of the subjects completed the 2 wk trial and returned for the follow-up visit. One of the subjects did not return for the $2 \mathrm{wk}$ follow-up visit, but provided some limited feedback on the telephone. This subject (S4) had a large lateral tilt of his neck and did not find the elastic head support to be useful for his condition. The remaining sections describe the results of the six subjects that finished the $2 \mathrm{wk}$ trial.

Subject S6 was unable to speak because of ALS, but communicated using an eye gaze communication board with four messages for the subject to select (Yes, No, I don't understand, I have a question). Subject S6 also used an $\mathrm{ABC}$ eye gaze spelling board to provide summative feedback.

Cervical range of motion measurements showed reduced range of motion of the neck compared to within normal limits measurements (Table 1); however, all subjects had a range of motion that included a neutral flexion/ extension angle. Subjects presented with symptoms suggesting spinal $(n=2)$, bulbar $(n=2)$, and mixed $(n=2)$ onset of ALS (Table 2). Four of the six subjects were community ambulatory at the time of the study (Table 2).

Table 1.

Neck range of motion (ROM) measurements $\left({ }^{\circ}\right)$.

\begin{tabular}{lccc}
\hline Subject & $\begin{array}{c}\text { Active ROM } \\
\text { Flexion }\end{array}$ & $\begin{array}{c}\text { Active ROM } \\
\text { Extension }\end{array}$ & $\begin{array}{c}\text { Passive ROM } \\
\text { Extension }\end{array}$ \\
\hline S1 & 28.3 & 26.3 & 25.0 \\
S2 & 46.6 & 23.6 & 23.0 \\
S3 & 41.0 & 26.6 & 18.3 \\
S5 & 44.6 & 22.6 & 29.3 \\
S6 & 9.0 & 13.0 & 17.3 \\
S7 & 7.0 & 59.0 & 72.7 \\
WNL & 50 & 60 & 60 \\
\hline WNL = within normal limits [8]. & \\
\hline
\end{tabular}

Table 2.

Amyotrophic lateral sclerosis (ALS) onset and ambulatory status of research subjects.

\begin{tabular}{lcc}
\hline Subject & ALS Onset $^{*}$ & Community Ambulatory $^{\text {S }}$ \\
\hline S1 & Spinal & Yes \\
S2 & Bulbar & No \\
S3 & Spinal & Yes \\
S5 & Bulbar & Yes \\
S6 & Mixed & No \\
S7 & Mixed & Yes \\
\hline
\end{tabular}

*Hillel AD, Miller RM, Yorkston K, McDonald E, Norris FH, Konikow N. Amyotrophic lateral sclerosis severity scale. Neuroepidemiology. 1989;8(3): 142-50. 
Four of the six subjects (S2, S3, S5, and S7) stated that they would recommend the elastic head support for others. Subject S2 had improvements in communication efficacy, eating and swallowing, hours of sitting prior to discomfort, and comfort in social situations (Table 3). He also had a reduction in his level of neck discomfort when using the elastic head support. Subject S2 had a slight increase in his level of breathlessness, from slight to moderate breathlessness, when using the elastic head support. Subject S2 rated the elastic head support at 10/10 (Table 4) and stated "I love it!" Subject S2 did not rate other head support systems he had used, but stated that they did not work for him. Subject S3 also had improvements in communication efficacy, eating and swallowing, and hours of sitting prior to discomfort. Unlike subject S2, subject S3 experienced a reduction in breathlessness, from moderate to none, when using the elastic head support. Although the elastic head support provided benefits to subject S3, its use reduced his comfort in social situations on the 10-point scale (from 10 to 8). Subject S3 elaborated by stating, "I don't think it is appropriate to wear a hat in your house or in a restaurant." Although this rating was reduced, subject S3 indicated that the elastic head support did make him more comfortable in general, adding "It's a little easier to eat, too, and I don't end up with my chin on my chest at the end of the day." Subject S3 rated the elastic head support at 9/10, rating other systems much lower (Table 4). Subject S5 had a reduction in breathlessness, from moderate to none, when using the elastic head support. He also indicated a slight improvement in his comfort in social situations and in the number of hours of sitting prior to discomfort. Subject S5 did experience slightly more neck discomfort when using the elastic head support, although both levels (pre and post) were low. Subject S5 indicated that he had strength in the sides and back of his neck but not in the front and that the device pulled his head back during sitting. He found the device useful during walking, but not for eating or sitting. Subject S5 rated the elastic head support at 8/10,

Table 3.

Responses (pre- and posttesting) to standardized tests and questionnaire in Appendix 1 (available online only). Improvements are shown in dark gray and negative outcomes are shown in light gray.

\begin{tabular}{|c|c|c|c|c|c|c|}
\hline \multirow{2}{*}{ Measure } & \multicolumn{6}{|c|}{ Subject } \\
\hline & S1 & $\mathbf{S 2}$ & S3 & S5 & S6 & S7 \\
\hline \multicolumn{7}{|c|}{ Modified Borg Scale-Rating of Perceived Dyspnea* } \\
\hline Pre & 0 & 2 & 3 & 3 & 0 & 0 \\
\hline Post & 2 & 3 & 0 & 0 & 0 & 0 \\
\hline \multicolumn{7}{|c|}{ Communication Effectiveness Scale for Individuals with ALS $^{\dagger}$} \\
\hline Pre & 4.8 & 1.4 & 4.7 & 2.6 & 1.0 & 1.2 \\
\hline Post & 4.8 & 2.2 & 5.0 & 2.6 & 1.0 & 1.2 \\
\hline \multicolumn{7}{|l|}{ Eating Assessment Tool ${ }^{\ddagger}$} \\
\hline Pre & 0 & 35 & 1 & 35 & 40 & 33 \\
\hline Post & 0 & 14 & 0 & 35 & 40 & 33 \\
\hline \multicolumn{7}{|l|}{ Level of Neck Discomfort $(0-10)$} \\
\hline Pre & 0 & 5 & $0-1$ & 0 & 5 & 5 \\
\hline Post & 0 & 2 & 0 & 1 & 7 & 5 \\
\hline \multicolumn{7}{|l|}{ Hours Sitting Before Discomfort } \\
\hline Pre & $>6$ & $0-1$ & $1-3$ & $0-1$ & $1-3$ & $1-3$ \\
\hline Post & $3-5$ & $>6$ & $>6$ & $5-6$ & $3-5$ & $1-3$ \\
\hline \multicolumn{7}{|l|}{ Hours Standing Before Discomfort } \\
\hline Pre & $0-1$ & $0-1$ & $0-1$ & $0-1$ & $0-1$ & $0-1$ \\
\hline Post & $0-1$ & $0-1$ & $1-3$ & $0-1$ & $0-1$ & $0-1$ \\
\hline \multicolumn{7}{|l|}{ Comfort in Social Settings (0-10) } \\
\hline Pre & 10 & 5 & 10 & 7 & 8 & 2 \\
\hline Post & 10 & 10 & 8 & 8 & 7 & 1 \\
\hline $\begin{array}{l}{ }_{*}^{*} 0=\text { no breathlessness at all, } 10=\text { maximum brea } \\
{ }^{\dagger} 1=\text { not understood, } 5=\text { effectively understood, } \\
{ }_{0} 0=\text { no problem, } 40=\text { severe problem. } \\
\text { ALS = amyotrophic lateral sclerosis. }\end{array}$ & & & & & & \\
\hline
\end{tabular}


Table 4.

Responses to questionnaire in Appendix 2 (available online only).

\begin{tabular}{|c|c|c|c|c|c|c|}
\hline \multirow{2}{*}{ Question } & \multicolumn{6}{|c|}{ Subject } \\
\hline & S1 & S2 & S3 & S5 & S6 & S7 \\
\hline $\begin{array}{l}\text { How often did you use } \\
\text { the elastic head support? }\end{array}$ & $\begin{array}{l}\text { Several times } \\
\text { per day }\end{array}$ & $\begin{array}{l}\text { Several times } \\
\text { per day }\end{array}$ & Daily & $\begin{array}{l}10 \text { times for } \\
8 \text { h total }\end{array}$ & Daily & $\begin{array}{l}5 \text { times for } \\
\text { about } 2 \text { h per } \\
\text { time }\end{array}$ \\
\hline $\begin{array}{l}\text { What activities did you } \\
\text { find the head support to } \\
\text { be useful? }\end{array}$ & All activities & All activities & All activities & While walking & All activities & $\begin{array}{l}\text { Watching } \\
\text { television }\end{array}$ \\
\hline $\begin{array}{l}\text { What activities did you } \\
\text { find the head support to } \\
\text { be not useful? }\end{array}$ & None & Sleeping & $\begin{array}{l}\text { Going to the } \\
\text { bathroom }\end{array}$ & Eating, sitting & None & $\begin{array}{l}\text { Normal } \\
\text { activities }\end{array}$ \\
\hline $\begin{array}{l}\text { Have you used other } \\
\text { types of head supports? }\end{array}$ & $\begin{array}{l}\text { Yes: cervical } \\
\text { soft collar }\end{array}$ & $\begin{array}{l}\text { Yes: none } \\
\text { listed }\end{array}$ & $\begin{array}{l}\text { Yes: none } \\
\text { listed }\end{array}$ & $\begin{array}{l}\text { Yes: rigid and } \\
\text { soft cervical } \\
\text { collar }\end{array}$ & $\begin{array}{l}\text { Yes: none } \\
\text { listed }\end{array}$ & $\begin{array}{l}\text { Yes: soft } \\
\text { cervical collar }\end{array}$ \\
\hline $\begin{array}{l}\text { Has elastic head support } \\
\text { made you more comfort- } \\
\text { able in social settings? }\end{array}$ & No & Yes & Yes & Yes & No & No \\
\hline $\begin{array}{l}\text { Can you rank the other } \\
\text { systems you have used } \\
\text { on a scale of } 0-10 \text { on } \\
\text { scale of overall } \\
\text { satisfaction? }\end{array}$ & $\begin{array}{l}\text { Elastic head } \\
\text { support: } 0 / 10 \text {; } \\
\text { soft cervical } \\
\text { collar: } 5 / 10\end{array}$ & $\begin{array}{l}\text { Elastic head } \\
\text { support: } 10 / 10\end{array}$ & $\begin{array}{l}\text { Elastic head } \\
\text { support: } 9 / 10 \text {; } \\
\text { soft cervical } \\
\text { collar: 5/10; } \\
\text { rigid collar: } \\
2-3 / 10\end{array}$ & $\begin{array}{l}\text { Elastic head } \\
\text { support: } 8 / 10 \text {; } \\
\text { soft cervical } \\
\text { collar: } 2 / 10 \text {; } \\
\text { rigid cervical } \\
\text { collar: } 1 / 10\end{array}$ & Others: 4/10 & $\begin{array}{l}\text { Elastic head } \\
\text { support: } 4 / 10 \text {; } \\
\text { soft cervical } \\
\text { collar: } 5 / 10\end{array}$ \\
\hline
\end{tabular}

rating other systems much lower (Table 4). Subject S7 did not experience improvements in the outcome measures and had a slight reduction in his comfort in social situations. Subject S7 stated that the elastic head support was useful for watching television, but not useful for "normal activities" because it was pulling his head back too much, the suspender clips were bothering him, and the Velcro was not holding. Subject S7 also commented about the social stigma of wearing a hat indoors. Despite the difficulties subject S7 had with the elastic head support system, he would recommend it for others to try because it may help them.

Two of the six subjects (S1 and S6) would not recommend the elastic head support for others. Subject S1 had increases in breathlessness, from none to slight, when using the elastic head support and also had a reduction in the hours of sitting prior to discomfort. Subject S1 rated the elastic head support at $0 / 10$, stating that it provided the same support as his soft cervical collar, but that the pressure from the hat on his forehead was "unbearable." Sub- ject S1 also mentioned that the elastic head support required more assistance in the bathroom than the soft cervical collar, which was difficult given the diminishing condition of his caregiver, and that it pulled his trousers up too high. Subject S1 rated the soft cervical collar at 5/10. Subject $\mathrm{S} 6$ had a slight increase in the number of hours of sitting prior to discomfort, but also experienced an increase in neck discomfort when using the elastic head support and a slight decrease in his comfort in social situations.

The most common reports of adverse reactions during use of the elastic head support were related to discomfort on the forehead, sometimes causing headaches. Padding was added to the brim of the baseball cap for some of the subjects in the follow-up session and that reduced the level of discomfort. Another negative aspect of using the elastic head support was difficulty toileting when the subject had reduced upper-limb function or when caregiver support was limited. 


\section{DISCUSSION}

Neck muscle weakness in patients with ALS can result in head drop (or involuntary anterior flexion of the neck). Patients presenting with this condition often complain of neck pain and stiffness due to an inability to hold their head up and maintain a neutral, upright position. Patients also report embarrassment regarding this compromised posture because they are often unable to make eye contact during conversation when their chin is on their chest. This study examined the potential benefits of using an elastic head support system, including possible effects on communication efficacy, swallowing function, and respiratory function.

The results of this study suggest that use of the elastic head support should be considered for management of head drop in patients with neck muscle weakness secondary to ALS. The device was found to be effective for some patients, but not for others. Two of the six subjects found that the device improved their communication efficacy at home and in the community. This improvement was attributed to improved posture, which allowed for better eye contact and visual cues for their communication partners attending to lip movement and facial expressions; increased breath support for speech production was also reported. Two of the six subjects reported that respiratory function declined from pretest to posttest, but the changes in this outcome were slight. It is possible that the elastic head support could cause shortness of breath if placed too tightly. A follow-up soon after applying the device could be helpful in correcting this and other issues. Further studies may wish to incorporate pulmonary function tests, which could be performed with the patient in and out of the device.

Although the data from this study are inadequate to provide specific prescription criteria for the device, they provide a first impression of patients who may or may not find the elastic head support useful as their primary head support system. Before fitting a patient with a device, clinicians should consider social views of wearing hats indoors, caregiver support, upper-limb function, and loose-fitting clothing. Patients who are very uncomfortable wearing hats indoors may not want to use the elastic head support as their only head support system. Patients with limited upper-limb function or limited caregiver support may find it difficult to remove the elastic head support for toileting. Additionally, loose-fitting pants are likely to cause discomfort when wearing the device because of a tendency for the pants to ride upward on the patient. The device is designed to work primarily in the sagittal plane and should be considered contraindicated for persons with large lateral tilting of the neck. Also, patients should be instructed to tighten the strap only enough to compensate for the weight of the head to avoid fatigue in neck flexors, shortness of breath, and/or neck pain from hyperextension. Additionally, the strap length should be set up to try and accommodate both sitting and standing. It is possible that the strap length should be adjusted slightly longer for sitting tasks. During fitting, the clinician should check the strap lengths for both sitting and standing and can place marks on the strap to indicate these settings for the patient or his or her caregiver. Also, it is possible that straps with more or less compliance than the ones used in this study would be more effective for certain patients. Lastly, a comfortable hat should be chosen and padding may be necessary between the hat and the forehead to prevent excessive pressure on the forehead. Periods of rest and/or alternating with other head supports may also be necessary.

Previous research [2] indicated that a baseball cap orthosis is effective for some patients in managing head drop. The intervention utilized a baseball cap with an adjustable buckle and an elastic band secured to the hat with Velcro, similar to our device. However, the baseball cap orthosis differed from our device in that it anchored the elastic band to a second band around the rib cage. When shown a picture of that orthosis, it was recognized as problematic by some of the subjects in our study because of the potential complications that could result from irritation (or even displacement) of percutaneous endoscopic gastrostomy tubes. Moreover, participants expressed concern about a strap around their rib cage because it could restrict breathing and exacerbate shortness of breath. However, a few patients indicated that the strap around the rib cage could make toileting easier. Both the baseball cap orthosis and our elastic head support are simple and inexpensive to make. Benefits and drawbacks of one design versus the other may need to be made clinically on a case-by-case basis.

The primary limitation of our study is the lack of comparative devices with similar trial periods. Future studies could provide multiple head support systems to patients simultaneously and have the subjects report on the systems that work best for their various activities of daily living or could supply different head support systems in a random order, with equal accommodation time for each device. The former approach may be preferred given the relatively low cost of these systems. It is highly likely that a combination of devices would provide the best care for patients, 
allowing them to change between different support strategies, especially as their disease progresses over time. An additional visit, shortly after providing the elastic head support, would be useful to make any necessary adjustments to the device (e.g., adjust strap length, add padding to hat).

\section{CONCLUSIONS}

The elastic head support system was effective for some, but not all, of the subjects in the study. The results of this study provide first impressions of the patients who may or may not benefit from use of the device as their primary head support system. For example, those who are socially comfortable wearing hats indoors, those with good upper-limb function or good caregiver support, and those who do not wear loose-fitting pants may find the elastic head support to be a highly useful head support system. Larger studies could help to establish clearer prescription criteria for the device. Given the low cost of materials and minimal time involved in fitting a patient with the device, clinicians should be able to try using the elastic head support for patients with neck extensor weakness on a caseby-case basis and/or as a supplement to other head support systems, in appropriately selected patients.

\section{ACKNOWLEDGMENTS}

\section{Author Contributions:}

Design of elastic head support system: A. Hansen, E. Nickel, G. Goldish. Study design: A. Hansen, B. Bedore, E. Nickel, K. Hanowski, S. Tangen, G. Goldish.

Acquisition of data: A. Hansen, B. Bedore, E. Nickel, K. Hanowski, S. Tangen.

Analysis and interpretation of data: A. Hansen, B. Bedore, E. Nickel, K. Hanowski, S. Tangen, G. Goldish.

Drafting of manuscript: A. Hansen, B. Bedore, K. Hanowski, S. Tangen. Critical revision of manuscript for important intellectual content: A. Hansen, B. Bedore, E. Nickel, K. Hanowski, S. Tangen, G. Goldish.

Study supervision: A. Hansen, G. Goldish.

Financial Disclosures: The authors have declared that no competing interests exist.

Funding/Support: At the time of the study, Dr. Hansen and Mr. Nickel were supported by the VA, Veterans Health Administration, Rehabilitation Research and Development Service (grants A6567R, A6568R, A7656P, A9224P, and A0618P to Dr. Hansen). Hats for the project were donated by the Minnesota Veterans Medical Research and Education Foundation.

Institutional Review: Research subjects first went through a consent process approved by the Minneapolis VA’s Institutional Review Board.
Participant Follow-Up: The authors do not plan to inform participants of the publication of this study.

\section{REFERENCES}

1. Gourie-Devi M, Nalini A, Sandhya S. Early or late appearance of "dropped head syndrome" in amyotrophic lateral sclerosis. J Neurol Neurosurg Psychiatry. 2003;74(5):683-86.

[PMID:12700323] http://dx.doi.org/10.1136/jnnp.74.5.683

2. Fast A, Thomas MA. The "baseball cap orthosis": A simple solution for dropped head syndrome. Am J Phys Med Rehabil. 2008;87(1):71-73. [PMID:17993989] http://dx.doi.org/10.1097/PHM.0b013e31815b6712

3. Borg GA. Psychophysical bases of perceived exertion. Med Sci Sports Exerc. 1982;14(5):377-81. [PMID:7154893] http://dx.doi.org/10.1249/00005768-198205000-00012

4. Burdon JG, Juniper EF, Killian KJ, Hargreave FE, Campbell EJ. The perception of breathlessness in asthma. Am Rev Respir Dis. 1982;126(5):825-28. [PMID:7149447]

5. Simon PM, Schwartzstein RM, Weiss JW, Lahive K, Fencl V, Teghtsoonian M, Weinberger SE. Distinguishable sensations of breathlessness induced in normal volunteers. Am Rev Respir Dis. 1989;140(4):1021-27. [PMID:2508520] http://dx.doi.org/10.1164/ajrccm/140.4.1021

6. Ball LJ, Beukelman DR, Pattee GL. Communication effectiveness of individuals with amyotrophic lateral sclerosis. J Commun Disord. 2004;37(3):197-215. [PMID:15063143] http://dx.doi.org/10.1016/j.jcomdis.2003.09.002

7. Belafsky PC, Mouadeb DA, Rees CJ, Pryor JC, Postma GN, Allen J, Leonard RJ. Validity and reliability of the Eating Assessment Tool (EAT-10). Ann Otol Rhinol Laryngol. 2008;117(12):919-24. [PMID:19140539]

8. Norkin CC, White DJ. Measurement of joint motion: A guide to goniometry. 3rd ed. Philadelphia (PA): F. A. Davis Co; 2003.

Submitted for publication March 25, 2013. Accepted in revised form September 20, 2013.

This article and any supplementary material should be cited as follows:

Hansen A, Bedore B, Nickel E, Hanowski K, Tangen S, Goldish G. Elastic head support for persons with amyotrophic lateral sclerosis. J Rehabil Res Dev. 2014;51(2): 297-304.

http://dx.doi.org/10.1682/JRRD.2013.03.0072

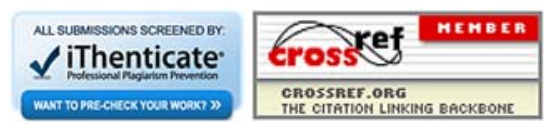


